which makes generalization difficult. Because of the retrospective design, certain laboratory results were sometimes unavailable on admission, including lactate dehydrogenase, D-dimer, and serum ferritin. Patients with chronic lung disease and conditions associated with immunosuppression were only a small percentage among hospitalized patients. Therefore, the role of some of these variables in predicting mortality from COVID-19 could have been underestimated.

In conclusion, calculation of the qSOFA score bedside at the time of admission can predict mortality among COVID-19 patients aged $\leq 65$ years. These findings can be applied globally, including resource-limited countries. Subsequent research involving multiple study sites and with a larger database can further validate the findings of our study.

\section{Acknowledgments.}

Financial support. This research did not receive any specific grants from funding agencies in the public, commercial, or not-for-profit sectors.

Conflicts of interest. All authors have no association that might pose a conflict of interest.

\section{References}

1. COVID-19 dashboard by the Center for Systems Science and Engineering (CSSE) at Johns Hopkins University (JHU). Johns Hopkins University website. https://coronavirus.jhu.edu/map.html. Published 2020. Accessed October 13, 2020.
2. US Centers for Disease Control and Prevention. Severe outcomes among patients with coronavirus disease 2019 (COVID-19)—United States, February 12-March 16, 2020. Morb Mortal Wkly Rep 2020;69:343-346.

3. Charlson ME, Pompei P, Ales KL, MacKenzie CR. A new method of classifying prognostic comorbidity in longitudinal studies: development and validation. J Chronic Dis 1987;40:373-383.

4. Ioannidis JPA, Axfors C, Contopoulos-Ioannidis DG. Population-Level COVID-19 mortality risk for non-elderly individuals overall and for non-elderly individuals without underlying diseases in pandemic epicenters. Environ Res 2020;188:109890.

5. Freund Y, Lemachatti N, Krastinova E, et al. Prognostic accuracy of Sepsis-3 criteria for in-hospital mortality among patients with suspected infection presenting to the emergency department. JAMA 2017;317:301-308.

6. Jiang SQ, Huang QF, Xie WM, Lv C, Quan XQ. The association between severe COVID-19 and low platelet count: evidence from 31 observational studies involving 7613 participants. Br J Haematol 2020;190(1):e29-e33.

7. Wu Z, McGoogan JM. Characteristics of and important lessons from the coronavirus disease 2019 (COVID-19) outbreak in China: summary of a report of 72,314 cases from the Chinese Center for Disease Control and Prevention. JAMA 2020;323:1239-1242.

8. Kim L, Garg S, O'Halloran A, et al. Risk factors for intensive care unit admission and in-hospital mortality among hospitalized adults identified through the US Coronavirus Disease 2019 (COVID-19)-Associated Hospitalization Surveillance Network (COVID-NET) Clin Infect Dis 2020. doi: 10.1093/cid/ciaa10127.

9. Bhargava A, Fukushima EA, Levine $M$, et al. Predictors for severe COVID19 infection. Clin Infect Dis 2020. doi: 10.1093/cid/ciaa674.

10. Cunningham JW, Vaduganathan M, Claggett BL, et al. Clinical outcomes in young US adults hospitalized with COVID-19. JAMA Intern Med 2020. doi: 10.1001/jamainternmed.2020.5313.

\title{
Coronavirus disease 2019 vaccine hesitancy among children's hospital staff: A single-center survey
}

\author{
Larry K. Kociolek MD, $\mathrm{MSCl}^{1,2}$ (1), Jenny Elhadary PharmD ${ }^{1}$, Ravi Jhaveri MD ${ }^{1,2}$, Ami B. Patel MD, MPH ${ }^{1,2}$, \\ Brian Stahulak DNP, MBA ${ }^{1}$ and Jenifer Cartland $\mathrm{PhD}^{1,2}$ \\ ${ }^{1}$ Ann \& Robert H. Lurie Children's Hospital of Chicago, Chicago, Illinois and ${ }^{2}$ Northwestern University Feinberg School of Medicine, Chicago, Illinois
}

The Pfizer-BioNTech COVID-19 (BNT162b2) vaccine was authorized for emergency use on December $11,2020,{ }^{1}$ after demonstrating excellent efficacy and safety in a large phase 3 clinical trial in adults and adolescents. ${ }^{2}$ The Advisory Committee on Immunization Practices through the Centers for Disease Control and Prevention then recommended its use, ${ }^{1}$ prompting delivery to US hospitals for healthcare worker vaccination. To help guide our children's hospital workforce vaccine advocacy efforts, we designed a survey assessing frequency of vaccine hesitancy, characteristics of those reporting vaccine hesitancy, specific concerns, and communication preferences.

Author for correspondence: Larry K. Kociolek, E-mail: lkociolek@luriechildrens.org Cite this article: Kociolek LK, et al. (2021). Coronavirus disease 2019 vaccine hesitancy among children's hospital staff: A single-center survey. Infection Control \& Hospital Epidemiology, 42: 775-777, https://doi.org/10.1017/ice.2021.58

\section{Methods}

This survey was performed at the Ann \& Robert H. Lurie Children's Hospital of Chicago, a 360-bed academic free-standing children's hospital with multiple satellite outpatient and surgical centers. On December 21, 2020, the first day of administration of the PfizerBioNTech COVID-19 vaccine to our workforce, a 17-question electronic survey (Supplemental Material online) was sent to all individuals with an active Lurie Children's email address. This survey included all clinical (eg, attending physicians, housekeeping staff, advanced practice staff, and ancillary healthcare workers), and nonclinical (eg, administrative, support, and research) staff. After 3 e-mail reminders were sent, the survey was closed on January 13, 2021. The survey was anonymous, and all questions were optional. During the 2 weeks before the survey, vaccine information was communicated to staff through a virtual town hall, and answers to frequently asked questions were emailed to all staff. Statistical analyses were performed using Stata/IC version 16.0 software (StataCorp, College Station, TX). Descriptive statistics were measured, prevalence ratios were

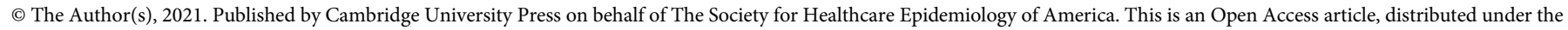
terms of the Creative Commons Attribution licence (http://creativecommons.org/licenses/by/4.0/), which permits unrestricted re-use, distribution, and reproduction in any medium, provided the original work is properly cited. 
Table 1. Demographics, Employment Characteristics, and COVID-19 Perceptions Associated With Vaccine Hesitancy

\begin{tabular}{|c|c|c|c|}
\hline Characteristic & $\begin{array}{c}\text { Vaccine Hesitant, } \\
\text { No. }(\%)\end{array}$ & $\begin{array}{c}\text { Not Vaccine Hesitant, } \\
\text { No. (\%) }\end{array}$ & $\begin{array}{l}\text { Prevalence Ratio } \\
\qquad(95 \% \mathrm{Cl})\end{array}$ \\
\hline \multicolumn{4}{|l|}{ Sex } \\
\hline Female $(n=3,377)$ & $668(19.8)$ & $2,709(80.2)$ & \multirow[t]{2}{*}{$1.7(1.4-2.2)^{*}$} \\
\hline Male $(n=759)$ & $86(11.3)$ & $673(88.7)$ & \\
\hline \multicolumn{4}{|l|}{ Race } \\
\hline Black $(n=411)$ & $207(50.4)$ & $204(49.6)$ & \multirow[t]{2}{*}{$3.2(2.9-3.6)^{*}$} \\
\hline Not black $(n=3,866)$ & $603(15.6)$ & $3,263(84.4)$ & \\
\hline \multicolumn{4}{|l|}{ Ethnicity } \\
\hline Hispanic/Latinx $(n=612)$ & $183(29.9)$ & $429(70.1)$ & \multirow[t]{2}{*}{$1.7(1.5-2.0)^{*}$} \\
\hline Not Hispanic/Latinx $(n=3,665)$ & $627(17.1)$ & $3,038(82.9)$ & \\
\hline \multicolumn{4}{|l|}{ Age, y } \\
\hline$\leq 40(n=2,312)$ & $423(18.3)$ & $1,889(81.7)$ & \multirow[t]{2}{*}{$0.99(0.87-1.1)$} \\
\hline$\geq 41(n=1,855)$ & $344(18.5)$ & $1,511(81.5)$ & \\
\hline \multicolumn{4}{|l|}{ History of COVID-19 } \\
\hline Confirmed or suspected history of COVID-19 $(n=602)$ & $181(30.1)$ & $421(69.9)$ & \multirow[t]{2}{*}{$1.8(1.5-2.0)^{*}$} \\
\hline No history of COVID-19 $(n=3,667)$ & $625(17.0)$ & $3,042(83.0)$ & \\
\hline \multicolumn{4}{|l|}{ Personal concern for COVID-19 risk } \\
\hline Not concerned about severe COVID-19 $(n=2,514)$ & $489(19.5)$ & $2,025(80.5)$ & \multirow[t]{2}{*}{$1.7(1.4-2.0)^{*}$} \\
\hline Concerned about severe COVID-19 $(n=1,148)$ & $133(11.6)$ & $1,015(88.4)$ & \\
\hline \multicolumn{4}{|l|}{ High-risk medical conditions } \\
\hline Yes $(n=459)$ & $214(46.6)$ & $245(53.4)$ & \multirow[t]{2}{*}{$3.0(2.7-3.4)^{*}$} \\
\hline No or unsure $(n=3,795)$ & $585(15.4)$ & $3,210(84.6)$ & \\
\hline \multicolumn{4}{|l|}{ Medical center role } \\
\hline Nonclinical $(n=1,615)$ & $463(28.7)$ & $1,152(71.3)$ & \multirow[t]{2}{*}{$2.4(2.1-2.8)^{*}$} \\
\hline Clinical $(n=2,568)$ & $305(11.9)$ & $2,263(88.1)$ & \\
\hline \multicolumn{4}{|l|}{ Employment type } \\
\hline Hourly employee $(n=1,879)$ & $519(27.6)$ & $1,350(72.4)$ & \multirow[t]{2}{*}{$2.4(2.1-2.8)^{*}$} \\
\hline Salaried employee $(n=2,317)$ & $264(11.4)$ & $2,053(88.6)$ & \\
\hline
\end{tabular}

Note. $\mathrm{Cl}$, confidence interval.

${ }^{\star} P<.01$ on both bivariate and multivariate analysis.

calculated, and proportions were compared using the $\chi^{2}$ test. Twosided $P$ values $<.05$ were considered statistically significant. Variables that were statistically significant on bivariate analysis were analyzed by multivariate logistic regression.

This study was exempt from institutional review board review as a quality improvement initiative using anonymous data.

\section{Results}

The survey was sent to 7,012 individuals, and 4,448 responded (response rate, 63.4\%). Most reported that they will definitely receive the vaccine $(n=2,559,59.8 \%)$, and $368(8.6 \%)$ had already received the vaccine. Vaccine hesitancy, defined as those reporting that they definitely will not $(n=193)$, probably will not $(n=185)$, or have not yet decided $(n=432)$ whether they will receive the COVID-19 vaccine, was reported in 810 of 4,277 respondents (18.9\%). Table 1 identifies demographics, employment characteristics, and COVID-19 perceptions associated with vaccine hesitancy. Among those who reported vaccine hesitancy, Table S1 (online) lists the prevalence of specific concerns, and Tables S2 and S3 (online) list the preferred COVID-19 vaccine educational resources and information dissemination methods.

\section{Discussion}

We identified COVID-19 vaccine hesitancy among nearly $20 \%$ of our children's hospital work force. Vaccine hesitancy was more prevalent among members of our work force who identify as female, black, and/or Hispanic/Latinx. These race- and ethnicity-related associations have been described for COVID-19 vaccination ${ }^{3}$ and are particularly concerning given the disproportionate impact of COVID-19 incidence and severity in black and Hispanic/ Latinx populations in the United States. ${ }^{4}$ Not surprisingly, vaccine hesitancy was associated with less concern about personal risk of severe COVID-19. Unexpectedly, vaccine hesitancy was 3 times more prevalent among individuals who identify themselves as having high-risk medical conditions, further highlighting the need for vaccine advocacy efforts among vulnerable patient populations. 
We identified specific COVID-19 concerns, especially concerns about vaccine safety related to novelty and speed of the clinical development process. Those expressing vaccine hesitancy identified their own medical doctor and national and local experts as trustworthy sources who can influence their vaccine decisions. Notably, social media was not valued as a tool for vaccine information, which is reassuring given the role of social media in disseminating vaccine misinformation. ${ }^{5}$

These data have equipped our COVID-19 response team with knowledge to develop targeted vaccine education and advocacy strategies. With these data, we have planned the following 5-part program for our work force: (1) small group discussions with members of our environmental services, security, and food services department employees led by infectious diseases experts and physician leaders who identify as black and/ or Hispanic/Latinx; (2) website link with answers to frequently asked questions that is accessible by smartphone; (3) vaccine information brochures in Spanish and English; (4) regular email updates and virtual town hall meetings with question and answer sessions; and (5) videos of hospital clinical and administrative leaders receiving and discussing their decision to receive the vaccine. We plan additional advocacy and education efforts for the community.

Although this survey was performed after vaccine safety and efficacy data were available and initiation of hospital vaccine education efforts, the frequency of vaccine hesitancy was similar to the $22 \%$ vaccine hesitancy prevalence among nearly 2,000 non-healthcare workers in the United States who were surveyed prior to authorization of COVID-19 vaccines in the United States. ${ }^{3}$ Although the survey was limited to a single pediatric center, this frequency of hesitancy may suggest that our data may be generalizable beyond our center.

This study has several limitations. Although the response rate was robust, we failed to receive responses from approximately onethird of our workforce. Because this survey was anonymous, we were unable to determine the characteristics of nonrespondents compared to respondents. The survey was completed immediately after the authorization of COVID-19 vaccine in the United States. It is unclear whether ongoing vaccine experience and uptake have impacted vaccine hesitancy since that time.

In summary, through an electronic survey of our children's hospital workforce, we identified characteristics associated with vaccine hesitancy and identified specific concerns and communication preferences of our vaccine hesitant staff. These data have guided development of targeted vaccine education and advocacy strategies to improve the health of our workforce and safety of our healthcare environment.

Supplementary material. To view supplementary material for this article, please visit https://doi.org/10.1017/ice.2021.58

Financial support. No financial support was provided relevant to this article.

Conflicts of interest. L.K.K. reports receiving a research grant from Merck, outside the scope of this study. No other authors report conflicts of interest.

\section{References}

1. Oliver SE, Gargano JW, Marin M, et al. The Advisory Committee on Immunization Practices interim recommendation for use of PfizerBioNTech COVID-19 vaccine-United States, December 2020. Morbid Mortal Wkly Rep 2020;69:1922-1924.

2. Polack FP, Thomas SJ, Kitchin N, et al. Safety and efficacy of the BNT162b2 mRNA COVID-19 vaccine. N Engl J Med 2020;383:2603-2615.

3. Khubchandani J, Sharma S, Price JH, Wiblishauser MJ, Sharma M, Webb FJ. COVID-19 vaccination hesitancy in the United States: a rapid national assessment. J Commun Health 2021. doi: 10.1007/s10900-020-00958-x.

4. Stokes EK, Zambrano LD, Anderson KN, et al. Coronavirus disease 2019 case surveillance-United States, January 22-May 30, 2020. Morbid Mortal Wkly Rep 2020;69:759-65.

5. Puri N, Coomes EA, Haghbayan H, Gunaratne K. Social media and vaccine hesitancy: new updates for the era of COVID-19 and globalized infectious diseases. Hum Vacc Immunotherapeut 2020;16:2586-2593. 